\title{
Informational Efficiency: An Empirical Test In Asian Currency Crisis
}

\author{
Zhaohui Zhang, Long Island University, Brookville \\ Khondkar E. Karim, Rochester Institute of Technology
}

\begin{abstract}
In this paper, we examine whether the trading of the equities of the U.S. international lenders was informationally efficient when the IMF announced its term loan agreement concerning South Korea in late 1997. More specifically, we test whether the foreign exposure levels of different lenders can be distinguished and used by investors to rapidly price the lenders' stocks proportionally according to the foreign exposure levels. A cross-sectional CAR regression model is used. The evidence indicates that the market is informationally efficient in trading the lenders' equities during the IMF assistance of South Korea as investors incorporated the foreign exposure into pricing their bank equities rapidly and proportionally. There is a significant positive relationship between the banks' equity prices and their respective exposure levels on the event days. This relationship is not shown on the nonevent dates.
\end{abstract}

\section{INTRODUCTION}

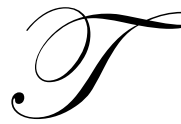

his paper examines the market informational efficiency hypothesis in the Asian currency crisis. Informational efficiency is tested as to how fast the news of the term loan announcements is incorporated into the equity pricing of U.S. banks that are lending in the international debt markets. We study how the IMF term loan announcements concerning South Korea in late November and early December 1997 affect informed trading of the equities of the U.S. international lenders to South Korea.

Similar hypotheses in international currency crisis are tested in Billingsley, et al. (1988), Cornell and Shapiro (1986), Smirlock and Kaufold (1987), Brunner and Simms (1987), Musumeci and Sinkey (1990a), Han and Wild (1990), Unal, et al. (1993), and Madura, et al. (1993), Demirguc-kunt and Huizinga (1993), Sinkey and Carter (1999), Zhang (2001), etc. Cornell and Shapiro (1986) find that without disclosure investors were able to distinguish between banks with extensive foreign loans and those with lesser or no foreign exposure during the 1982 Mexican foreign debt moratorium. Their findings support the "dribs and drabs" hypothesis, which holds that negative news was slowly absorbed by the market during the event window. Bruner and Simms (1987) find that over the first few days following the 1982 Mexican debt moratorium event, bank lenders were penalized inconsistently with their degree of exposure indicating contagion pricing. However, the market learned very quickly and the pricing of the bank stocks corrected after the initial five days indicating rational pricing thereafter. Smirlock and Kaufold (1987) also find, for the August 1982 Mexican debt moratorium, that the stock price response is proportional to exposure and that investors were able to distinguish among the exposure levels of different banks.

Madura, Tucker and Zarruk (1992) study the reaction of bank stock prices to the Third-world Debt Reduction Plan (DRP) of 1989, which was proposed by the World Bank to international bank creditors, allowing them to swap existing bank debt for more secure debt or equity of Less-Developed Countries (LDCs). They find the degree of change in equity values was positively associated with the bank's degree of exposure to the debt of less developed countries. For exposed banks, the rational pricing hypothesis is supported - market investors seem to be able to distinguish the lending exposure levels correctly. Unal, Demirguc-kunt and Leung (1993) study the stock market's reaction to the announcement of the Brady plan and the Mexican debt-reduction agreement in 1989. For U.S. banks, the Brady announcement caused multinational banks to have significant positive returns. The gain was not uniform 
across banks and it had no significant impact on non-multinational banks. They also find that the price response is not linearly proportional to exposure.

In this paper, we investigate the effect of IMF term loans to South Korea on the equity values of U.S. bank lenders during late November and early December 1997. Theoretically, banks that had high exposures to South Korea would have been more heavily and negatively impacted than banks that had low exposures if the IMF had not lent to South Korea. As such, the equity values of the former would have been more negatively affected than those of the latter. Because of the IMF term loans, the results are expected to be opposite, namely, the banks that were more heavily exposed to South Korea are expected to have more positive return impacts than the banks that had less exposure to South Korea. Are investors informed of the financial fundamentals of those international lenders quickly enough? If yes, presumably, the cumulative returns should not be significant, while only the event day abnormal returns should be significant. If otherwise, then the new information is probably much slowly absorbed by the market ("dribs and drabs" hypothesis in previous literature), additional requirements for banks to publish more detailed balance sheet data may be needed.

The paper proceeds as follows: Section II provides the background of the IMF term loans to South Korea around late November and early December 1997. Section III presents the data and methodology. Section IV presents the results while Section V concludes the paper

\section{BACKGROUND}

The event window in this study is from November 13, 1997, the date Mr. Camdessus (the IMF head then) was asked by South Korean officials to come over, to December 31, 1997, the ending date of the two-year sample period.

Two critical individual announcements are chosen for the IMF term loan to South Korea: December 1, 1997 (Monday) is the day zero in this study. It is the first trading day after South Korea announced unilaterally that a bailout agreement had been reached between its government and the IMF. This event announcement is hypothesized to contain significant positive new information international lenders, especially those to South Korea.

The second event is December 4, 1997 (Thursday, day three in this study) when the news of the final official bailout agreement fully reached the markets. This event announcement is also hypothesized to contain significantly positive new information to international lenders for resolving any remaining uncertainties about the bailout. The remaining uncertainties as to when the final agreement would be reached were aggravated especially after the South Korean government backed off an earlier announcement (day zero) saying that a final deal was not done.

\section{DATA AND METHODOLOGY}

The sample is composed of all twenty-seven U.S. banks that had foreign loan exposure at the end of 1997. The twenty-seven foreign exposed banks with their respective foreign exposure are shown in Table 1. The potential overlapping "other events" in the event window screened from the Wall Street Journal and the Lexis ${ }^{\circledR}$-Nexis ${ }^{\circledR}$ Academic Universe database include mergers and acquisitions (M\&As), legislative changes and earnings information. However, only events related to M\&As are considered to be relevant. ${ }^{1}$ Because of the lack of general market and banking industry events, the sampled banks involved in M\&As are not excluded from the final sample and the inferences are drawn on the portfolio basis. Any confounding effect is believed to be minimal at best.

\footnotetext{
${ }^{1}$ These are recorded on a daily basis from $11 / 25 / 97$ to $12 / 31 / 97$, available upon request.
} 
Table 1: All Foreign Exposed U.S. Banks (as of end of 1997)

All numbers except those in column (3) are in million dollars as of the end of 1997. "n.a." indicates the bank's South Korean foreign exposure is below $1 \%$ or $0.75 \%$ of total assets. According to the Federal Financial Institutions Examination Council (FFIEC) regulation, when the foreign exposure level in a country, it is less than $1 \%$ is not required to be reported.

\begin{tabular}{|l|c|c|c|c|}
\hline Bank & Ticker & Exposure & Value & Ratio \\
\hline & & $(1)$ & $(2)$ & $=(1) /(2)$ \\
\hline Citicorp & CCI & 42500 & 19293 & 2.2029 \\
\hline Chase Manhattan Corp & CMB & 42744 & 20002 & 2.1370 \\
\hline Bankers Trust Corp & BT & 9955 & 5050 & 1.9713 \\
\hline Morgan (J P) \& Co & JPM & 18176 & 10710 & 1.6971 \\
\hline Bank Of New York Co Inc & BK & 7776 & 4947 & 1.5719 \\
\hline BankAmerica Corp & BAC & 28532 & 19223 & 1.4843 \\
\hline First Chicago NBD Corp & FCN/NBD & 4515 & 7770 & 0.5811 \\
\hline BankBoston Corp & BKB & 12568 & 4332 & 2.9012 \\
\hline Pacific Century Financial & BOH & 1609 & 1117 & 1.4399 \\
\hline Republic New York Corp & RNB & 4176 & 2938 & 1.4213 \\
\hline Riggs National Corporation & RIGS & 390 & 459 & 0.8485 \\
\hline Comerica Inc & CMA & 2085 & 2512 & 0.8301 \\
\hline State Street Corp & STT & 1569 & 1995 & 0.7865 \\
\hline CoreStates Financial Corp & CFL & 2454 & 3237 & 0.7581 \\
\hline UnionBancal Corp & UNBC & 1399 & 2532 & 0.5527 \\
\hline First Hawaiian Inc & FHWN & 339 & 732 & 0.4634 \\
\hline Mellon Bank Corp & MEL & 1566 & 3652 & 0.4288 \\
\hline Northern Trust Corp & NTRS & 470 & 1619 & 0.2904 \\
\hline NationsBank Corp & NB & 4697 & 21274 & 0.2208 \\
\hline MBNA Corp & KRB & 599 & 1970 & 0.2174 \\
\hline Norwest Corp & NOB & 1076 & 6834 & 0.1575 \\
\hline Wachovia Corp & WB & 639 & 5174 & 0.1236 \\
\hline Union Planters Corp & UPC & 207 & 1692 & 0.1225 \\
\hline First Union Corp (N C) & FTU & 1431 & 12032 & 0.1189 \\
\hline SunTrust Banks Inc & STI & 247 & 5199 & 0.0476 \\
\hline Sterling Bancorp & STL & 0.79 & 90 & 0.0088 \\
\hline Wells Fargo \& Co & 79 & 12614 & 0.0063 \\
\hline
\end{tabular}

Balance sheet data are from COMPUSTAT, the National Information Center, Keefe, Bruyette \& Woods, Inc., bank annual reports, and 10-K reports filed with the Securities and Exchange Commission (SEC). Daily stock returns and value weighted market indexes are obtained from the Center for Research in Security Prices (CRSP) database from January 2, 1996 to December 31, 1997.

In this study, the foreign lending exposure variable is defined as the foreign loans divided by the bank's book value of equity. Book value of equity, rather than market value of equity or total assets, is used because it is most related to the default risk that is the concern of the regulators.

Models and Hypothesis

The abnormal return for each bank in the sample is obtained based on the following two-index market model:

$R_{i t}=\alpha_{i}+\beta_{i} R_{m, t}+\gamma_{i} I_{t}+\varepsilon_{i t}$

where $R_{m t}$ represents a typical market index (value-weighted CRSP index in this study), $I_{t}$ is an index representing unexpected interest rate changes (AR(1) of a 30-year T-bond rate series in this study). The estimation window for the market model is from January 2, 1996 to June 30, 1997 (379 observations). The trading period from July 1, 1997 to 
the start of the event window is excluded to eliminate the impact on equity pricing by potential structural changes caused by the outbreak of the Asian crisis. ${ }^{2}$

The market informational efficiency hypothesis is tested using the following cross-sectional regression:

$\mathrm{CAR}_{\mathrm{i}}\left(\mathrm{t}_{1}, \mathrm{t}_{2}\right)=\beta_{1}+\beta_{2}\left(\mathrm{EX}_{\mathrm{i}}\right)+\beta_{3}\left(\mathrm{EX}_{\mathrm{i}}\right)^{2}+\eta_{\mathrm{i}}$

where $\operatorname{CAR}_{i}\left(t_{1}, t_{2}\right)$ is the cumulative abnormal return for bank $i$ from $t_{1}$ (also the event day zero in this study) to $t_{2}$ (day one, two or three in the tests.) $\mathrm{EX}_{\mathrm{i}}$ represents the exposure of bank $\mathrm{i}$. Its coefficients represent both a linear and a quadratic relationship between the cumulative abnormal returns and the exposure levels across banks. Under the FDICIA's Prompt Correction Action (PCA) provisions, even the largest banks will be disciplined by the regulators promptly if their capital positions deteriorate and fall below the requirements. Regulatory forbearance thus is reduced extensively as opposed to circumstances before the Act was passed. Since a potential significant capital loss will cause the credit risk of the TBTF banks to increase dramatically, thus increasing the regulatory sanctions on them, using a quadratic function to describe the relationship between the abnormal returns and the relative exposure levels for the banks may very well be justified.

The semi-strong form of market efficiency says that market is informationally efficient when security prices correctly reflect all publicly available information at once (Fama, 1991). In this study, we test market informational efficiency as to whether market investors react to the IMF announcements regarding South Korea in late 1997 fast enough to incorporate those international lenders' fundamental financial information into the stock prices. ${ }^{3}$ We hypothesize the most important financial information be the foreign exposure variable, considering the link between the IMF term loan announcements and the impacts on the international lenders' equities is through the lenders' foreign exposure (loans and investment) in those countries in crisis. As such, the new information would be composed mainly the timing and the interpretation of the announcements and the accuracy of any reports on the financial statements of the lenders, especially their foreign exposure variable.

If not only a single individual announcement is significant but the cumulative announcements are significant as well, then it implies that investors needed more time to react to news announcements ("dribs and drabs" hypothesis) and that not all the information was available to everyone in the market at the time when the announcements were made. This is especially true when single individual abnormal returns on event dates are not significant but cumulative abnormal returns are. However, if the model is significant only on the individual event days, but not over nonevent dates, then it implies that the market absorbs and reflects the new information fully and rapidly and the market is informationally efficient. That is, we investigate the rapidity of the market's response and the duration of investors' response to the IMF term loan announcements to South Korea during late 1997. The interpretation from testing this hypothesis will draw upon the comparisons between the impact of individual announcements and cumulative announcements revealed using Model (2). If the market is not informationally efficient, then additional requirements for banks to publish more detailed balance sheet data may be needed.

\section{EMPIRICAL FINDINGS}

If the international debt markets are informationally efficient, then the news of IMF term loan announcements should be incorporated into the equity prices immediately, and the abnormal returns of the foreign exposed banks should be significant on the event dates but insignificant on the nonevent dates. Since the IMF term loan announcements happen in the international debt markets, equity returns of banks with foreign exposures are directly affected and the effect should be proportional to the changes in the foreign exposure variable. Thus, the existence of market informational efficiency can be examined by observing whether the coefficient estimates of the foreign exposure variable are significant in terms of equity pricing on both the event dates and nonevent dates. Market

\footnotetext{
${ }^{2}$ However, we did run the test without omitting the date period from the estimation window, the results are similar even though slightly less significant as the return variance during the crisis is understandably higher.

${ }^{3}$ As the test of market efficiency is always a joint test, we assume the simple models used in this study are correctly specified and expected returns are correctly estimated.
} 
informational efficiency through the cross-sectional relationship between banks' equity return responses and their respective exposure levels is examined by Model (2).

If market efficiency is rejected here, meaning the significance of the models was present on nonevent dates or the models are not significant on event dates, this could be because the market is indeed not efficient or an incorrect model is used. If it is assumed that Model (2) is correctly specified and the parameter estimate of the exposure variable is significantly different from zero on event dates and not significant on nonevent dates, then the evidence of market informational efficiency exists related to the announcements of IMF term loans to South Korea in early December 1997. Presumably, the higher the foreign exposure a bank had, the higher a positive return the bank should yield, since the IMF loan commitment was assumed to be a positive event in international debt markets.

Since only twenty-seven banks (number of observations in this cross-sectional analysis) have foreign lending exposure, the test is thus sensitive to the underlying normality assumption, constant variance assumption and the existence of the outliers of the model. The relevant diagnosis tests (normality tests calculating the Pearson correlation coefficients between the actual residuals and predicted residuals and the examination of outliers from the residual plots) are conducted on the sample and the normality test results are reported in Table 2.

Table 2: Normality Tests for the Cross-sectional Regression Model

The CAR model CAR $\mathrm{C}_{\mathrm{i}}(\mathrm{t} 1, \mathrm{t} 2)=\beta_{1}+\beta_{2}\left(\mathrm{EX}_{\mathrm{i}}\right)+\beta_{3}\left(\mathrm{EX}_{\mathrm{i}}\right)^{2}+\eta_{\mathrm{i}}$ is tested for all 27 foreign exposed banks. Each CAR interval below produces an estimated regression model. $\operatorname{Car}(0)=\mathrm{AR}(0)$. The last regression model uses $\mathrm{CAR}=\mathrm{CAR}(0)+\mathrm{AR}(3)$. The critical value for $\mathrm{n}=27$ at the $5 \%$ significance level is about 0.961. The estimated correlation coefficient $\mathrm{r}$ is the Pearson correlation estimates between the ordered residuals and the expected residuals W-p is the p-value of Shapiro-Wilk W-statistic.

\begin{tabular}{|c|c|c|c|c|}
\hline & \multicolumn{2}{|c|}{ Full Model } & \multicolumn{2}{c|}{ Without $\left(\mathbf{E X}_{\mathbf{i}}\right)^{\mathbf{2}}$} \\
\hline CAR Interval & $\mathbf{r}$ & $\mathbf{W}-\mathbf{p}$ & $\mathbf{r}$ & $\mathbf{W}-\mathbf{p}$ \\
\hline 0 & 0.9838 & 0.8265 & 0.9773 & 0.6299 \\
\hline$(0,+1)$ & 0.9743 & 0.0882 & 0.9718 & 0.0590 \\
\hline$(0,+2)$ & 0.9778 & 0.3753 & 0.9791 & 0.4530 \\
\hline$(0,+3)$ & 0.9883 & 0.7895 & 0.9873 & 0.6783 \\
\hline$(0),(+3)$ & 0.9813 & 0.2340 & 0.9665 & 0.0494 \\
\hline
\end{tabular}

The estimated correlation coefficients of the actual residuals and the expected residuals on the five CAR regressions in Table 2 are all significant at the 5 percent level. We fail to reject normality in every case. Neither any serious outliers nor the violation of the constant variance assumption is found in the models from the examination of the models' residual plots.

Tables 3 to 5 present the results from the cross-sectional CAR regression Model (2). The five CAR regressions are run with each conducted on a single day from day zero to day three. The fifth one uses the ARs just for day zero and day three. In Table 3, on December 1, the model's F-value is 4.695 with a p-value of 0.0190. R-square is $28.12 \%$. While the model is significant, neither the linear coefficient estimate nor the quadratic coefficient estimate is significant. The p-values for the linear and quadratic coefficient estimates are 0.6124 and 0.7645 , respectively. The variance inflation factor between the two independent variables is 14.33 , which indicates strong presence of multicollinearity. As such, models are run with either the linear exposure or quadratic exposure variable alone, the results are reported in Table 4 and 5, respectively. 
Table 3: The Estimated Cross-sectional Regression Models (Full Models)

The CAR model $\mathrm{CAR}_{\mathrm{i}}(\mathrm{t} 1, \mathrm{t} 2)=\beta_{1}+\beta_{2}\left(\mathrm{EX}_{\mathrm{i}}\right)+\beta_{3}\left(\mathrm{EX}_{\mathrm{i}}\right)^{2}+\eta_{\mathrm{i}}$ is tested for all 27 foreign exposed banks. The estimated correlation coefficient $r$ is the Pearson correlation estimates between the ordered residuals and the expected residuals. P-values are in parentheses. Each CAR interval below produces an estimated regression model. $\operatorname{Car}(0)=\mathrm{AR}(0)$. The last regression model uses $\mathrm{CAR}=\mathrm{CAR}(0)+\mathrm{AR}(3)$. The null hypothesis is: $\beta_{2}=\beta_{3}=0$, the alternative hypothesis is: Not both betas are zero. P-values are in the parentheses. VIF is 14.33 in each test above, indicating the existence of the multicollinearity.

\begin{tabular}{|c|c|c|c|c|c|}
\hline Event Date & F-value & $\beta_{1}$ & $\boldsymbol{\beta}_{2}$ & $\boldsymbol{\beta}_{3}$ & R-square \\
\hline \multirow{2}{*}{0} & $4.695 * *$ & 0.0111 & 0.0074 & 0.0019 & \multirow{2}{*}{$28.12 \%$} \\
\hline & $(0.0190)$ & $(0.0489)$ & $(0.6124)$ & $(0.7645)$ & \\
\hline \multirow{2}{*}{$(0,+1)$} & 1.472 & 0.0172 & 0.0047 & 0.0007 & \multirow{2}{*}{$10.93 \%$} \\
\hline & $(0.2495)$ & $(0.0025)$ & $(0.7357)$ & $(0.9095)$ & \\
\hline \multirow{2}{*}{$(0,+2)$} & 0.668 & 0.0181 & 0.0130 & -0.0029 & \multirow{2}{*}{$5.27 \%$} \\
\hline & $(0.5221)$ & $(0.0412)$ & $(0.5700)$ & $(0.7737)$ & \\
\hline \multirow{2}{*}{$(0,+3)$} & 1.217 & 0.0354 & -0.0191 & 0.0139 & \multirow{2}{*}{$9.21 \%$} \\
\hline & $(0.3237)$ & $(0.0081)$ & $(0.5680)$ & $(0.3560)$ & \\
\hline \multirow{2}{*}{$(0),(+3)$} & $4.220 * *$ & 0.0284 & -0.0247 & 0.0187 & \multirow{2}{*}{$26.02 \%$} \\
\hline & $(0.0269)$ & $(0.0056)$ & $(0.3354)$ & $(0.1078)$ & \\
\hline
\end{tabular}

**: indicates the significance at the $5 \%$ level.

Table 4: The Estimated Cross-sectional Regression Models (With Quadratic Term Only)

The CAR model $\mathrm{CAR}_{\mathrm{i}}(\mathrm{t} 1, \mathrm{t} 2)=\beta_{1}+\beta_{3}\left(\mathrm{EX}_{\mathrm{i}}\right)^{2}+\eta_{\mathrm{i}}$ is tested for all 27 foreign exposed banks. The estimated correlation coefficient $r$ is the Pearson correlation estimates between the ordered residuals and the expected residuals. P-values are in parentheses. Each CAR interval below produces an estimated regression model. $\operatorname{Car}(0)=\operatorname{AR}(0)$. The last regression model uses $\mathrm{CAR}=\mathrm{CAR}(0)+\operatorname{AR}(3)$. The null hypothesis is: $\beta_{3}=0$, the alternative hypothesis is: Not both betas are zero. $\mathrm{P}$-values are in the parentheses.

\begin{tabular}{|c|c|c|c|c|}
\hline Event Date & F-value & $\beta_{1}$ & $\boldsymbol{\beta}_{3}$ & R-square \\
\hline \multirow{2}{*}{0} & $9.404 * * *$ & .0132 & $.0051 * * *$ & \multirow{2}{*}{$27.33 \%$} \\
\hline & $(0.0051)$ & $0.0006)$ & $0.0051)$ & \\
\hline \multirow{2}{*}{$(0,+1)$} & $2.931 *$ & .0186 & $0.0027 *$ & \multirow{2}{*}{$10.49 \%$} \\
\hline & $(0.0993)$ & $.0001)$ & 0.0993) & \\
\hline \multirow{2}{*}{$(0,+2)$} & 1.032 & .0218 & .0027 & \multirow{2}{*}{$96 \%$} \\
\hline & $(0.3195)$ & $0.0003)$ & $(0.3195)$ & \\
\hline \multirow{2}{*}{$(0,+3)$} & 2.157 & .0299 & 0.0056 & \multirow{2}{*}{$7.94 \%$} \\
\hline & $(0.1544)$ & $0.0007)$ & $(0.1544)$ & \\
\hline \multirow{2}{*}{$(0),(+3)$} & $7.483 * *$ & .0213 & $.0081 * *$ & \multirow{2}{*}{$3.04 \%$} \\
\hline & $(0.0113)$ & $(0.0014)$ & $0.0113)$ & \\
\hline
\end{tabular}

$* * *, * *, *$ : indicate the significance at the $1 \%, 5 \%$ and $10 \%$ level, respectively.

In Table 4, when the linear exposure term is excluded from the model, on day zero, the F-value increases to 9.404 with a p-value of 0.0051 . In Table 5 , when the quadratic exposure term is excluded from the model, on the same day, the F-value increases to 9.649 with a p-value of 0.0047 . Other results are also very similar. Either the linear or quadratic exposure term alone is good enough to explain the return behavior, only the results from the model without the quadratic term are detailed below. 
Table 5: The Estimated Cross-sectional Regression Models (With Linear Term Only)

The CAR model CAR $\mathrm{C}_{\mathrm{i}}(\mathrm{t} 1, \mathrm{t} 2)=\beta_{1}+\beta_{2}\left(\mathrm{EX}_{\mathrm{i}}\right)+\eta_{\mathrm{i}}$ is tested for all 27 foreign exposed banks. The estimated correlation coefficient $r$ is the Pearson correlation estimates between the ordered residuals and the expected residuals. P-values are in parentheses. Each CAR interval below produces an estimated regression model. $\operatorname{Car}(0)=\mathrm{AR}(0)$. The last regression model uses $\mathrm{CAR}=$ $\mathrm{CAR}(0)+\operatorname{AR}(3)$. The null hypothesis is: $\beta_{2}=0$, the alternative hypothesis is: Not both betas are zero. P-values are in the parentheses.

\begin{tabular}{|c|c|c|c|c|}
\hline Event Date & F-value & $\boldsymbol{\beta}_{\mathbf{1}}$ & $\boldsymbol{\beta}_{\mathbf{2}}$ & \multirow{2}{*}{ R-square } \\
\hline \multirow{2}{*}{0} & $9.649^{* * *}$ & 0.0101 & $.0016^{* * *}$ & \multirow{2}{*}{$27.85 \%$} \\
\cline { 2 - 4 } & $(0.0047)$ & $(0.0089)$ & $(0.0047)$ & \\
\cline { 2 - 4 }$(0,+1)$ & $3.051^{*}$ & 0.0168 & $0.0062^{*}$ & \multirow{2}{*}{$10.88 \%$} \\
\cline { 2 - 4 }$(0,+2)$ & $(0.0930)$ & $(0002)$ & $(0.0930)$ & \\
\cline { 2 - 4 } & 1.299 & 0.0197 & 0.0067 & \multirow{2}{*}{$4.94 \%$} \\
\hline \multirow{2}{*}{$(0,+3)$} & $(0.2653)$ & $(0.0043)$ & $(0.2653)$ & \multirow{2}{*}{$5.86 \%$} \\
\cline { 2 - 4 } & $(0.2238)$ & $(0.0061)$ & 0.0109 & $(0.2238)$ \\
\multirow{2}{*}{$(0),(+3)$} & $5.271^{* *}$ & 0.0183 & $0.0158^{* *}$ & \multirow{2}{*}{$17.41 \%$} \\
\cline { 2 - 4 } & $(0.0303)$ & $0.0201)$ & $(0.0303)$ & \\
\hline
\end{tabular}

$* * *, * *, *$ : indicate the significance at the $1 \%, 5 \%$ and $10 \%$ level, respectively.

In Table 5, the five CAR regressions are run with each conducted on a single day from day 0 to day 3 . The fifth regression uses the ARs for day 0 and day 3. Because the abnormal returns on day 2 are not significant, not surprisingly, the two-day cumulative return regression yields an F-value of 3.051 with a p-value of 0.0930. The Rsquare decreases to 10.88 percent from 27.85 percent on day zero. The three-day cumulative regression yields an Fvalue of 1.299 with a p-value of 0.2653 . The R-square is only 4.94 percent. The cumulative regression on December 4 , including the impacts from both events simultaneously, is not significant at 5 percent. This is not surprising because the abnormal returns on both day 2 and day 3 are not significant. The F-value is 1.556 and its p-value is 0.2238 . The cumulative regression is also run using the two event days' abnormal returns while leaving the abnormal returns on day +1 and day +2 out. The F-value is 5.271 with a p-value of 0.0303 .

In sum, the CAR models on day zero and the cumulative regression of ARs just on day zero and day three are significant, indicating that there is a strong positive relationship between the banks' equity returns and their respective foreign lending exposure levels. The changes of equity returns were proportional to the foreign exposure levels. It is worth noting that the CAR models are not significant from day one to day three. Based on the evidence above, the IMF term loan announcement news was incorporated into the equity pricing fairly quickly and the markets seemed to be informationally efficient. While it is not clear which exposure variable, linear or quadratic, is more important, the exposure variable appears to be important on the event dates and is not considered as important on the nonevent dates as it was on the event dates.

\section{CONCLUSIONS}

This paper examines the market informational efficiency hypothesis in the international currency crisis. By examining the link between the IMF term loan announcements and the impacts on the international lenders' equities through the lenders' foreign exposure (loans and investment) in those countries in crisis, we investigate the rapidity of the market's response and the duration of investors' response to the IMF term loan announcements to South Korea in late 1997.

We find that for the foreign exposed banks, the foreign exposure tends to be significant on event dates but insignificant on nonevent dates. The evidence indicates that the market is informationally efficient during the IMF bailout of South Korea in late 1997 as investors incorporated the foreign exposure into pricing their bank equities 
rapidly and proportionally. There is a significant positive relationship between the banks' equity prices and their respective exposure levels on the event days. This relationship is not shown on the nonevent dates.

\section{REFERENCES}

1. Billingsley, R., Lamy, S., and Robert, E., 1988, The regulation of international lending -- IMF support, the debt crisis, and bank stockholder wealth, Journal of Banking and Finance 12, 255-274.

2. Bruner, R. F. and Simms, J. M., 1987, The international debt crisis and bank security returns in 1982, Journal of Money, Credit and Banking 19(1), 46-55.

3. Cornell, Bradford, and Shapiro, Alan C., 1986, The reaction of bank stock prices to the international debt crisis, Journal of Banking and Finance, 10, 55-73.

4. Demirguc Kunt, A. and Huizinga, H., 1993, Official credits to developing countries: implicit transfers to the banks, Journal of Money, Credit, and Banking 25, Part 1.

5. $\quad$ Fama, Eugene F., 1991. Efficient capital markets II, Journal of Finance 46, 1575-1617.

6. Han, J. and Wild, J., 1990, Unexpected earnings and intra-industry information transfers: Further evidence, Journal of Accounting Research 28(1), 211-219.

7. Madura, J., Tucker, A.L., and Zarruk, E., 1993, Market reaction to the thrift bailout, Journal of Banking and Finance 17(4), 591-608.

8. Musumeci, J. J. and Sinkey, J. F., Jr. 1990, The international debt crisis, investor contagion, and bank security returns in 1987: The Brazilian experience, Journal of Money, Credit, and Banking 22, 209-220.

9. Sinkey, J. F. and Greenwalt, M., 1991, Loan-loss experience and risk-taking behavior at large commercial banks, Journal of Financial Services Research 5, 43-59.

10. Sinkey, J. F. and Carter, D. A., 1999, The reaction of bank stock prices to news of derivatives losses by corporate clients, Journal of Banking and Finance 23, 1725-1743.

11. Smirlock, M. and Kaufold H., 1987, Bank foreign lending, mandatory disclosure rules, and the reaction of bank stock prices to the Mexican debt crisis, Journal of Business 60(3), 347-364.

12. Unal, H., Demirguc-Kunt, A., and Leung, K.W., 1993, The Brady plan, 1989 Mexican debt-reduction agreement, and bank stock returns in United States and Japan, Journal of Money, Credit and Banking 25(3(Part 1)), 410-429.

13. Zhang, Z., 1993, The Impact of IMF Term Loans on U.S. Bank Creditors' Equity Values: An Event Study of South Korea's Case, Journal of International Financial Markets, Institutions and Money, Vol. 11, 2001, 363 394. 